\title{
A CONTRATRANSFERÊNCIA E A IMPORTÂNCIA DAS CAPACIDADES DO ANALISTA NA PRÁTICA PSICANALÍTICA CONTEMPORÂNEA
}

\author{
Countertransference and the importance of the analyst's \\ abilities in contemporary psychoanalytic practice
}

RESUMo Embora o uso da contratransferência seja um tema polêmico e a discussão sobre a participação da mente do analista possa remontar à antiga concepção de aptidão para a tarefa analítica com base em personalidade ou estrutura psicológica, o fato é que a formação do psicanalista envolve a elaboração de seus conflitos inconscientes, tornando conscientes as vias de seu desejo e de seus sintomas por meio de um processo de análise pessoal e de um longo treinamento teórico e técnico no campo da psicanálise. Este trabalho é uma revisão bibliográfica baseada nos estudos sobre a função materna, que tem como objetivo mostrar o caminho de valorização da contratransferência na teoria e técnica psicanalítica e a implicação das capacidades do analista no processo analítico. Esse desenvolvimento é tributário da valorização da função materna como modelo para a relação interpessoal e terapêutica em psicanálise, fruto do paradigma das relações de objeto na tradição da psicanálise inglesa, que tem em Donald W. Winnicott e Wilfred R. Bion dois de seus principais autores.

Palavras-chave ContratransferênCia; PSicanálise; ANALISTA; CLÍNICA PSICANALÍTICA.

ABStract Although the USE OF countertransference is a controversial topic and the debate on the participation of the analyst's mind may go back to the old conception of aptness for the analytical task based on personality or psychological makeup, the fact is that the psychoanalyst's education involves the elaboration of his unconscious conflicts, turning conscious the pathways of his desire and his symptoms through a process of personal analysis and a long theoretical and technical training in the field of psychoanalysis. This study is a literature review based on studies about the maternal function, which aims at showing the path of recovery of countertransference in psychoanalytic theory and technique and the implication of the analyst's abilities in the analytical process. This development is tributary of the appreciation of maternal function as a model for interpersonal and therapeutic relationship in Psychoanalysis, due to the paradigm of object relations in the British psychoanalytic tradition, being Donald W. Winnicott and Wilfred R. Bion two of its main authors.

KEYWORDS COUNTERTRANSFERENCE; PSYCHOANALYSIS; ANALYST; PSYCHOANALYTIC CLINIC.

Julia Girnos Elias de Souza Universidade Federal de São Carlos (UFSCAR) jugirnos@gmail.com

Érico Bruno Viana Campos Universidade Estadual Paulista Júlio de Mesquita (UNESP) ebcampos@fc.unesp.br

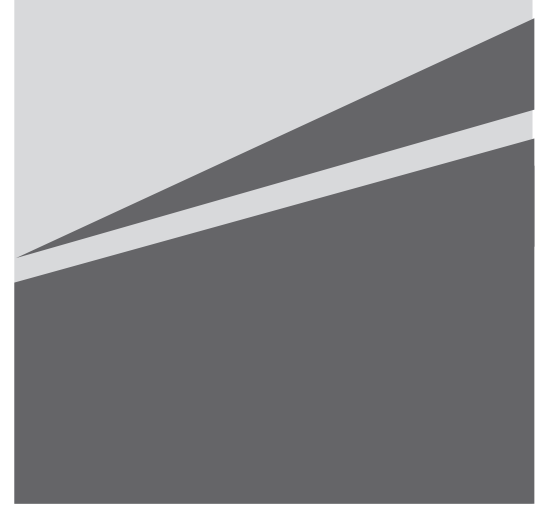




\section{INTRODUÇÃO}

$\mathrm{E}$ ste artigo pretende apresentar alguns dos desenvolvimentos da teoria da técnica analítica em direção ao reconhecimento do manejo contratransferencial como instrumento fundamental do processo psicanalítico, discutindo a implicação da mente do analista e sua capacidade de continência como competências necessárias para o trabaIho terapêutico e desenvolvimento da análise.

Embora o uso da contratransferência seja um tema polêmico, e a discussão sobre a participação da mente do analista possa remontar à antiga concepção de aptidão ou não da tarefa analítica com base em estruturas de personalidade, o fato é que a formação do psicanalista envolve a elaboração de seus conflitos inconscientes, tornando conscientes as vias de seu desejo e de seus sintomas por meio de um processo de análise pessoal e de um longo treinamento teórico e técnico no campo da psicanálise.

O intuito deste trabalho é mostrar como, ao longo da história, o desenvolvimento da teoria e da técnica psicanalítica foi cada vez mais valorizando os aspectos contratransferenciais do processo analítico, levando a uma maior implicação da mente do analista e de algumas capacidades emocionais muito específicas, que podem ser genericamente descritas como sustentação e continência. Esse desenvolvimento é tributário da valorização da função materna como modelo para a relação interpessoal e terapêutica em psicanálise, fruto do paradigma das relações de objeto na tradição da psicanálise inglesa, que tem em Donald W. Winnicott e Wilfred R. Bion dois de seus principais autores.

Acreditamos que a importância do olhar proposto sobre o analista e suas capacidades emocionais justifica-se pela clara influência que elas têm sobre o processo analítico. Freud (2006c), em sua conhecida metáfora entre a psicanálise e o jogo de xadrez, já falava da influência do analista no andamento do processo analítico ao afirmar que ambos os processos (o jogo de xadrez e a psicanálise) obedecem às mesmas regras de início e de fim, mas são seguidos de diferentes jogadas intermediárias cujos desfechos serão diferentes, dependendo da experiência e criatividade do enxadrista/analista.

Desse modo, o analista, ao exercer sua função, assume uma direção efetiva do processo que está realizando. Ele o faz em sua capacidade de escutar, ao dar o enquadre particular que utiliza para trabalhar na eleição das interpretações e em como as entrega ao paciente. Nesse sentido, dentro do modelo psicanalítico, os objetos da investigação analítica fazem parte também da vida psíquica do analista, e isso pode servir tanto para elucidar os fenômenos que ocorrem durante uma sessão quanto para ocultá-los.

Não é somente por meio da comunicação verbal do paciente ou da interpretação do analista que se promove o conhecimento e a estruturação de si mesmo; isso ocorre também por intermédio de uma relação intensa, íntima, empática e prolongada com o analista. Dentro de um ambiente propício, os pacientes revivem, com o analista, uma relação de dependência emocional própria de estágios mais primitivos da vida. Assim como o bebê, o paciente, muitas vezes, é incapaz de comunicar-se verbalmente, mas o faz por meio de uma comunicação silenciosa. Quando o profissional não é capaz de compreender o que seu paciente busca no tratamento, e persiste em um trabalho que não atende às suas necessidades psíquicas, é frequente que o processo terapêutico entre em uma situação de impasse.

Diante destas situações, nas quais geralmente são revividas experiências de angústia por ambas as partes, é essencial que o analista possa observar suas próprias vivências contratransferenciais para analisá-las, a fim de ampliar seu espaço mental, possibilitando um maior contato com a realidade psíquica de seus pacientes. Para isso, o analista precisa apoiar-se em um modelo teórico com o qual possa conceber, não só a natureza das relações transferenciais entre as figuras que preenchem a cena analítica, como também o fenômeno contratransferencial produzido em tal encontro. 
Ao propor um olhar acerca da importância das capacidades pessoais do analista, baseamo-nos na perspectiva de Winnicott e Bion sobre as funções maternas e seu papel na constituição do sujeito, entendendo que a função do analista é permitir a elaboração dos conflitos intrapsíquicos do paciente, fomentando funções e conteúdos psíquicos que não foram proporcionados ou desenvolvidos pelo ambiente ao longo do desenvolvimento emocional de sua personalidade. Assim, quando o desenvolvimento emocional primitivo falha, o analista pode dar ao paciente a oportunidade de resgate do desenvolvimento e elaboração de seus conflitos estruturantes. Essa possibilidade de reparação e elaboração das funções e conteúdos psíquicos, por sua vez, será proporcionada pela capacidade de manejo do campo transferencial-contratransferencial por parte do analista.

\section{BREVE COMENTÁRIO HISTÓRICO SOBRE A CONTRATRANSFERÊNCIA}

O conceito de contratransferência passou por gradativas mudanças ao longo do desenvolvimento da psicanálise e é, ainda hoje, um dos temas mais debatidos na área. Tanto o aprofundamento da compreensão acerca do fenômeno transferencial-contratransferencial quanto a possibilidade do uso da contratransferência como recurso na tarefa analítica foram vitais para o avanço da teoria e da técnica psicanalítica. Os conceitos de transferência e contratransferência tiveram evoluções históricas semelhantes, já que inicialmente esses fenômenos foram encarados como obstáculos e, gradativamente, vieram a ser elementos centrais da técnica psicanalítica. Porém, as ênfases em ambos foram diferenciadas ao longo desse processo histórico.

Diferente da contratransferência, a transferência é assunto recorrente e central na obra freudiana. É nos clássicos artigos sobre a técnica que o termo ganha o caráter de conceito verdadeiramente psicanalítico, passando a ser incluído na essência da relação terapêutica. Esse é o momento em que Freud (2006b) observa que a transferência tem a função de repetir, na análise, relações primordiais estabelecidas no passado por meio da figura do analista. Desde então, o manejo das interpretações e resistências no contexto da transferência consolidou-se como eixo de todo e qualquer processo psicanalítico.

Freud nunca elaborou uma sistematização sobre a contratransferência ou deu ao conceito um papel de destaque em sua teoria da técnica. Ele inaugura a abordagem do tema destacando seu aspecto negativo, considerando-o um obstáculo indesejável no trabalho analítico (FREUD, 2006a), tônica que marcou sua obra até o fim. Apesar de considerar que a resposta emocional do analista ao material inconsciente do paciente representava um obstáculo também para o progresso da psicanálise, o autor genialmente descreve que os conteúdos inconscientes do paciente podem ser captados pelo analista de uma forma muito singular, ao afirmar que "o médico deve voltar seu próprio inconsciente, como um órgão receptor, na direção do inconsciente transmissor do paciente. Deve ajustar-se ao paciente como um receptor telefônico se ajusta ao microfone transmissor" (FREUD, 2006b, p. 129). E continua, dizendo: "o inconsciente do médico é capaz, a partir de derivados do inconsciente que lhe são comunicados, de reconstruir esse inconsciente, que determinou as associações livres do paciente" (FREUD, 2006b, p. 129).

Dentro do pensamento freudiano, o diálogo entre o inconsciente do analista e o do analisando baseia-se na conjunção das associações livres e da atenção flutuante. Nesse momento, em que o terapeuta não é apenas um simples observador e intérprete do fenômeno da transferência, Freud passa a assinalar a importância das condições e preparo do analista para o exercício de suas funções.

Pouco foi publicado nos 40 anos que seguiram ao nascimento do conceito de contratransferência. Melanie Klein (1946-1963) manteve o essencial da concepção freudiana de que esse fenômeno constituía um obstáculo na análise. Para a autora, a contratransferência é entendida como uma reação do incons- 
ciente do analista às fantasias do paciente, que são projetadas nele, de forma que o fenômeno contratransferencial aparece como um ruído, uma interferência que precisa ser minimizada. O surgimento de novas ideias acerca dos aspectos positivos da contratransferência fez da década de 1950 um marco na teoria psicanalítica. Dentre estas novas ideias, os trabalhos de Paula Heimann e Heinrich Racker destacam-se pelo uso dado ao fenômeno contratransferencial, tido pelos autores como instrumento sensível e possivelmente útil para o desenvolvimento do processo analítico (EIZIRIK; AGUIAR; SCHESTATSKY, 2005).

Segundo Zimerman (1999), o desenvolvimento da teoria da contratransferência foi possível com o avanço sugerido pelo trabalho de Melanie Klein (1946-1963) e de seus seguidores no entendimento de mecanismos primitivos que participam do fenômeno contratransferencial, tais como os processos dissociativos (splitting) e de identificação projetiva.

Heinrich Racker considerava que a contratransferência poderia operar de três formas: como obstáculo, assim como é considerado no modelo clássico; como importante instrumento de comunicação e de compreensão das relações de objeto do paciente; e como um campo em que o paciente tem a possibilidade de vivenciar uma experiência diferente das que teve originalmente. Já para Heimann, o conceito englobava todas as reações que o analista experimenta diante de seu paciente. Em sua concepção, os sentimentos contratransferenciais originam-se no analista como produto do paciente e, portanto, constituem parte essencial da relação analítica. Nesse sentido, esses sentimentos do analista devem ser reconhecidos, ao invés de negados, pois só assim o analista poderá subordiná-los à tarefa analítica (ETCHEGOYEN, 2004).

Embora as ideias de instrumentalização dos sentimentos e emoções do analista como fonte de informação sobre o paciente, sugeridas por Heimann, nunca tenham sido aceitas por Klein, muitos de seus seguidores fizeram uso ampliado do conceito de contratransferência, considerando o fenômeno um estado mental total induzido no analista, resultado da comunicação verbal e não verbal do paciente (ZIMERMAN, 1999).

No esteio de um desenvolvimento independente no âmbito da psicanálise das relações de objeto, e em contraposição a certas proposições do movimento kleiniano, Winnicott (2000) publica o artigo "O ódio na contratransferência", trabalho no qual chamava atenção para os sentimentos contratransferenciais, que denomina de objetivos (medo e ódio) despertados nos profissionais pelos psicóticos, afirmando a necessidade do profissional ser capaz de odiar objetivamente. No desenvolver de sua teoria, o autor utiliza o termo de forma mais ampla e pensa na contratransferência em paralelo à preocupação materna, fenômeno necessário para que a mãe possa adaptar-se às necessidades de seu filho e ser suficientemente boa para seu desenvolvimento.

Já Bion (1994), mais próximo da teoria kleiniana, usou pela primeira vez a noção da identificação projetiva como ferramenta de uso na contratransferência, fundamental para a criação de seu modelo relacional continente-conteúdo, núcleo de seu modelo vincular em psicanálise (ZIMERMAN, 1999). Este par conceitual foi desenvolvido de modo progressivo pelo autor que, ao expor sua teoria sobre a capacidade de pensar, amplia o conceito kleiniano de identificação projetiva para além de uma fantasia onipotente, entendendo-o como um meio de comunicação primordial na relação primitiva mãe-bebê, assim como na relação analítica.

Considerando a possível instrumentalização do fenômeno contratransferencial na prática da clínica psicanalítica, tanto os conceitos de preocupação materna primária e mãe suficientemente boa de Winnicott quanto os conceitos de rêverie e função continente de Bion encaminham-nos para a importância da instrumentalização dos processos mentais do próprio analista para que o trabalho clínico progrida de forma satisfatória (SAFRA, 1995).

\section{WINNICOTT, O AMBIENTE E A SUSTENTAÇÃO}

Por meio de sua prática clínica e dos estudos sobre a constituição psíquica do sujei- 
to, Winnicott favoreceu o desenvolvimento de teoria psicanalítica no âmbito pré-representacional das experiências. Para o autor, o objetivo da análise, com alguns pacientes, é proporcionar um ambiente suficientemente bom que se adapte à necessidade que surge do verdadeiro self e dos processos de maturação, permitindo o abandono de organizações defensivas e a retomada do processo de amadurecimento (BARONE, 2011).

Winnicott (2005) salienta que existem tendências naturais em direção ao desenvolvimento e à independência, a não ser que sejam bloqueadas por falências de cuidados do ambiente. Quando o ambiente não se apresenta suficientemente bom, o indivíduo passa a reagir à intrusão, fazendo com que os processos de integração sejam interrompidos e o núcleo do self, ou seja, o self verdadeiro, que é mais próximo à vida pulsional do indivíduo, passa a se proteger. Quando este estado de paralisação no processo de desenvolvimento mantém-se, surge um falso self, construído sobre a base de uma submissão defensiva.

Nesse âmbito do desenvolvimento, o indivíduo ainda não dispõe de representações mentais, de modo que os afetos são vividos no registro do próprio corpo como agonias intoleráveis de aniquilamento, e não como angústias de castração ou de separação relacionadas à situação edípica. Para esses tipos de paciente, a interpretação nem sempre é proveitosa, já que a comunicação acontece de forma diferenciada. Assim, o ambiente tornase mais importante que a interpretação, e a manutenção de uma situação adaptativa a esse self é fundamental (BARONE, 2012).

Sendo assim, a essência da experiência do self reside na vivência da dependência destes cuidados ambientais. O mesmo acontece na clínica winnicottiana, de acordo com três etapas: a dependência absoluta, na qual o indivíduo pode apenas sofrer os cuidados do ambiente; a dependência relativa, em que existe algum tipo de consciência em relação ao cuidado e este pode ser relacionado aos impulsos pessoais e, por isso, passíveis de reprodução na transferência e; rumo à indepen- dência, pois o indivíduo é capaz de tolerar a ausência dos cuidados por meio do acúmulo de experiências positivas e da confiança na sustentação do ambiente que lhe foi provido (KHAN, 2000).

Inicialmente, o autor vincula o ambiente ao corpo materno como um aglomerado da percepção do bebê sobre os cuidados e sensações fisiológicas. À medida que sua própria teoria evolui, transcendendo a dicotomia kleiniana dos objetos parciais, o ambiente winnicottiano passa a ser uma construção relacional subjetiva, um terceiro subjetivo que inclui o corpo do bebê, a mãe e seus cuidados. Dessa forma, a mãe deixa de ser um objeto passivo da fantasia do bebê para tornar-se propriamente uma função constituinte do self. Este estado inicial de continuidade entre self e não self, cuja unidade não é o indivíduo isolado, mas, sim, o conjunto ambiente-indivíduo, é essencial para que o indivíduo possa confiar no ambiente (KLAUTAU; SALEM, 2009).

Winnicott (1990) notou que os pacientes que não obtiveram um ambiente suficientemente bom que gerasse confiança, no qual o verdadeiro self pudesse se constituir, exigiam do processo analítico adaptações específicas da técnica, de forma semelhante à exigência que é feita à mãe de ser capaz de perceber e adaptar-se às necessidades de seu bebê, chamada, pelo autor, de preocupação materna primária.

A preocupação materna primária torna a mãe capaz de identificar-se ativamente com as necessidades do bebê, nutrindo sua onipotência ao apresentar a ele o que precisa, quando precisa. Esta capacidade de perceber às necessidades do verdadeiro self faz-se necessária na prática clínica e torna-se possível a partir da instrumentalização da contratransferência do analista como uma forma de comunicação potencial. É a partir deste estado de sensibilidade, similar à "devoção" materna, que o analista poderá fornecer a sustentação necessária para o desenvolvimento de seu paciente.

Esta sustentação, ou o holding materno, diz respeito a uma provisão ambiental total 
que possibilita o desenvolvimento. Segundo Safra (1995), na clínica essa sustentação materna fica representada principalmente pela manutenção do setting constante e pela atitude respeitosa, atenta e não intrusiva do analista. Se esta condição for mantida, o analista poderá ser concebido, segundo a necessidade de constituição e de amadurecimento do indivíduo, como um objeto subjetivo que dá suporte às necessidades psíquicas momentâneas.

Uma destas necessidades é a de sentir-se real. Segundo as palavras de Winnicott, "é possível pensar no rosto da mãe como o protótipo do espelho. No rosto dela o bebê vê a si próprio. Se ela estiver deprimida ou preocupada com alguma outra coisa, então é claro que o bebê não verá nada além de um rosto" (2002, p. 89). A função espelho, que é baseada no processo de identificação primária com a mãe ou substituto, tece um cenário afetivo fundamental para que o indivíduo possa integrar uma imagem própria. Para o autor, o self não integrado não pode ser observado nem recordado pelo indivíduo, a menos que seja observado e espelhado de volta a ele.

A função de apresentar objetos é base para o processo criativo e a experiência de ilusão, estando diretamente ligada com a preocupação primária, uma vez que permite ao indivíduo viver a fantasia de onipotência mantida pelos cuidados constantes e a esperança de uma relação viva entre a realidade interna e externa. Contudo, essa experiência depende também da capacidade do objeto de sobreviver. A sobrevivência do analista é expressa principalmente na manutenção da postura ética do profissional (SAFRA, 1995).

Se o indivíduo precisar proteger o objeto em virtude de sua fragilidade, ele não o destruirá, e a destruição desempenhará papel central na criação da realidade. Para que o indivíduo perceba o mundo objetivamente, ele deve experimentar o objeto que sobrevive à sua destrutividade. A sobrevivência do objeto analista conduz ao seu uso, e este uso à separação de dois fenômenos distintos: a fantasia e o objeto real, fora da área de onipotência (JANUÁRIO; TAFURI, 2011).
Segundo Winnicott, "entre o paciente e o analista está a atitude profissional do analista, sua técnica, o trabalho que executa com sua mente" (1990, p. 148). Nesse sentido, um processo analítico suficientemente bom depende da habilidade do analista em escutar a comunicação de que seu paciente dispõe e, a partir dela, ser capaz de prover sustentação para que o desenvolvimento do verdadeiro self funcione como espelho e apresente objetos para seu uso, gerando um ambiente facilitador para o desenvolvimento da criatividade e espontaneidade.

Portanto, é a partir da valorização da dinâmica contratransferencial, baseada no reconhecimento da centralidade da dinâmica relacional dual mãe-bebê, que a análise suficientemente boa torna-se viável. Esta contribuição para a teoria da técnica vem no esteio das contribuições no campo da psicanálise das relações de objeto propostas por autores ligados ao grupo kleiniano e ao grupo independente. Nesse sentido, esta abordagem da capacidade de escuta do analista também será enfatizada por Bion em sua teoria da mente ao falar da necessidade que o indivíduo possui de encontrar um continente para suas vivências psíquicas.

\section{BION, RÊVERIE E A CONTINÊNCIA DO ANALISTA}

Ao formular a teoria acerca do pensamento, Bion (1994) considerou a mente um instrumento para simbolizar, conter e transformar sensações e sentimentos em elementos psíquicos passíveis de serem pensados, enfatizando que esse instrumento nasce e desenvolve-se em função da relação com o outro. Segundo Zimerman (1999), a conceituação de Bion a respeito do continente - mãe ou analista - constitui um dos postulados fundamentais da teoria e da prática psicanalítica atual.

Ao longo do desenvolvimento da teoria psicanalítica, houve uma ampliação na valorização da sensibilidade e da percepção para os estados da mente mais regredidos, incluindo maior atenção ao próprio estado mental e emocional do analista em função da maneira 
como seu paciente comporta-se na sessão, e emprega, ou não, a linguagem para comunicar-se (SALVITTI, 2011).

Com forte embasamento na teoria kleiniana, a originalidade da colaboração teórica de Bion está na compreensão da relação mãe-bebê como constituinte da mente, de uma forma que o papel materno transcende o prover de cuidados fisiológicos que possam conter a angústia para a provisão de representação mental. Nessa concepção, as pressões produzidas por experiências brutas, sem representação, inicialmente não se distinguem de vivências corporais. Algumas destas vivências vão se transformar em fatos mentais, chamados por Bion de elementos 6 , que não servem para serem pensados, e, por isso, mantêm-se como eventos da mesma natureza que os somáticos, ou são expelidos da mente por um processo projetivo de caráter evacuativo, ou ainda transformados em elementos $\alpha$ por meio da função $\alpha$ atuante da mãe (BARROS, 1999).

Para Bion, a identificação projetiva, além de ter a função de defesa do aparelho mental proposta por Klein, ou seja, de evacuar um estado mental insuportável a partir da fantasia onipotente de que partes indesejadas da personalidade podem ser projetadas para fora de si e para dentro do objeto, tem também a função de causar ao objeto estado mental semelhante ao seu como forma de comunicação. Nesse sentido, o bebê projeta a parte perturbadora de sua personalidade na mãe, que, recebendo este conteúdo com sua capacidade continente e percebendo tais comunicações em seu inconsciente, estabelece certa ordem no caos de sensações e pensamentos, podendo devolvê-la de modo mais tolerável para que o bebê possa internalizar o que era inicialmente seu (MELEGA, 2011).

Bion utilizou o termo rêverie para descrever esse componente da função materna, referindo-se ao estado psicológico que torna a mãe capaz de desempenhar adequadamente o papel de continente para as projeções de seu filho. Esse estado psicológico assemelha-se a um estado de sonho que permite à mãe captar o que se passa com seu filho, não pelos órgãos do sentido, mas pela retomada de uma unidade funcional, vivenciada anteriormente de forma física e fisiológica, elevando essa vivência para o plano da simbolização. Nesse conceito de sujeito que emerge da interação com o outro, a identificação projetiva passa a constituir um acontecimento psicológico interpessoal real com o recipiente da identificação projetiva, criando uma nova subjetividade por meio da dialética conteúdo-continente. Nessa dialética, projetor (filho) e recipiente (mãe) entram em um estado que pressupõe a existência de dois sujeitos, embora a subjetividade seja vivenciada simultaneamente com uma intersubjetividade única e como duas subjetividades possíveis (OGDEN, 1996).

Acreditamos ser válido aqui diferenciar que ser recipiente de um conteúdo projetado implica um processo passivo, no qual o outro somente recebe, enquanto ser continente diz respeito a um processo ativo, no qual o recipiente deve ser capaz de acolher, conter, decodificar e transformar (ZIMERMAN, 2009).

A função materna, como instrumento de simbolização da experiência emocional postulada por Bion, é responsável, não apenas pela transformação de percepções e emoções brutas em elementos $\alpha$, como pelo desenvolvimento destes últimos em diferentes níveis de simbolização e complexidade, bem como por seus distintos usos possíveis. Estes níveis de simbolização seriam: os elementos $B$, em que não há distinção entre objeto psíquico e objeto inanimado; os elementos $\alpha$, resultado do exercício da função $\alpha$, possibilitam a formação e uso de pensamentos oníricos; os pensamentos oníricos, os sonhos e mitos; a pré-concepção, um estado de expectativa; a concepção, uma variável que pode ser substituída por uma constante; o conceito, que advém liberto da concepção; o sistema dedutivo-científico, que é um conceito que se enreda em hipóteses por meio da lógica, e, por fim, o cálculo algébrico, que é o extremo da representação simbólica formal (BION, 1997).

Todos esses diferentes níveis e usos das formações psíquicas, incluindo fragmentos de 
funções psíquicas agregadas, gerados pela inversão da função $\alpha$ e chamados de "objetos bizarros" (BION, 1994), podem ser encontrados no espaço analítico, no analisando, no analista ou no par. A fim de encontrar uma categorização que facilitasse a compreensão posterior dos processos mentais ocorridos durante a sessão, Bion criou um modelo matemático que chamou de Grade, no qual organizou os níveis de simbolização e seus usos. Dentre estes, Bion enfatizou a importância da elaboração simbólica dos primeiros níveis de simbolização, já que todos os outros níveis, assim como a própria integração do ego, dependem fundamentalmente da existência prévia dos elementos $\beta$ e $\alpha$. (GROTSTEIN, 2010).

Na clínica, espera-se que o analista possa servir de continente, emprestando sua função $\alpha$ ao processo analítico, ajudando o paciente a dispor de elementos apropriados para o pensamento, permitindo ser alvo das identificações projetivas massivas de elementos $b$ do paciente, para transformá-los em elementos $\alpha$ (BION, 1991).

A capacidade de rêverie do analista e a atenção flutuante preconizada por Freud encontram-se, na medida em que a rêverie também diz respeito à sua capacidade de dar curso livre às suas associações e devaneios, e de relacionar-se com o paciente sem memória, sem desejo ou ânsia de compreensão (BION, 1991). Este estado pressupõe do analista uma disposição para conter estados de não saber, uma abertura ao desconhecido de cada situação e a capacidade de transformar em matéria simbólica aspectos dolorosos e insuportáveis da personalidade (ZIMERMAN, 2011).

É imprescindível à função de continência que o analista consiga sobreviver às diversas formas de destruição exercidas pelo paciente, pois, no fundo, nutre a esperança de que o analista sobreviva, sem revidar, sem se deprimir, sem ficar apático e desinteressado, quer dizer, sem abandoná-lo. Essa função de sobrevivência é particularmente importante porque estes ataques provocam reações contratransferenciais muito densas e difíceis de serem manejadas.

\section{CONCLUSÃO}

Partindo das propostas apresentadas no âmbito de um modelo intersubjetivo de sujeito, o papel do ambiente e, por consequência, das capacidades do analista de prover a ambientação suficientemente adequada para que o processo analítico aconteça passa a ser fundamental. Especialmente diante de situações de ataque, desinvestimento, ruptura ou intrusão, capazes de tornar inoperante a função de continência e sustentação do analista.

Nesses casos, faz-se fundamental a diferenciação conceitual da identificação projetiva na teoria kleiniana, que tem a finalidade de evacuar no analista o que não quer ou não pode sentir; e certa concepção de projeção discernível nas teorias de Bion e de Winnicott, nas quais o paciente evacua aquilo que ele espera que o analista sinta, como única forma que possui de comunicar o que precisa. Nesse sentido, as teorias de ambos os autores confluem para a valorização de uma função materna capaz de atuar como receptáculo ativo destas projeções, não apenas suportando e sobrevivendo a elas, mas constituindo e fomentando a elaboração psíquica (ZIMERMAN, 2009). Mais ainda, as contribuições de Winnicott e Bion, de valorização da função materna, são fundamentais para uma proposição original sobre a compreensão do vínculo transferencial-contratransferencial, em que a função interpretativa do analista amplia-se de forma considerável, passando a incluir sua mente e seu corpo como um instrumento fundamental do manejo técnico da análise.

Na clínica psicanalítica, assim como em qualquer outra profissão, devemos dispor de certo preparo que possibilite nosso trabalho. Nos primórdios da psicanálise foi postulado que a formação de um analista deve estar sustentada em um tripé constituído pelo ensino teórico, pela supervisão e pela análise pessoal do analista. Os avanços mais recentes, de autores como Winnicott e Bion, mostram-nos que essa formação implica diretamente a singularidade da experiência psicossomática do analista, com todas as suas respostas empáticas como um instrumento fundamental da 
técnica, e não apenas como um ruído ou interferência que deve ser suplantado por meio da auto-observação sistemática que reconheça a emergência de fantasias inconscientes, fruto, fundamentalmente, de processos do analista. Portanto, são contribuições fundamentais para pensar o processo psicanalítico como uma atividade intersubjetiva criativa e engajada.

\section{REFERÊNCIAS}

BARONE, K. Winnicott e a posição ética do analista. Impulso, Piracicaba, v. 21, n. 52, p. 75-86, 2012. Disponível em: <https://www.metodista.br/revistas/revistas-unimep/index.php/impulso/ article/view/332/586>. Acesso em: 13 ago. 2012.

BARROS, E. M. da R. O inconsciente e a constituição de significados na vida mental. Psicologia USP, São Paulo, v. 10, n. 1, 1999. Disponível em: <http://www.scielo.br/scielo.php?pid=S0103-65641999000100005\&script=sci_arttext>. Acesso em: 14 ago. 2012.

BION, W. R. As transformações. Rio de Janeiro: Imago, 1991. (Original de 1965).

. Uma teoria sobre o pensar: estudos psicanalíticos revisados. Rio de Janeiro: Imago, 1994. (Original de 1962).

. Elementos em psicanálise. Rio de Janeiro: Imago: 1997. (Original de 1963).

EIZIRIK, C. L.; AGUIAR, R. W.; SCHESTATSKY, S. S. et al. Psicoterapia de orientação analítica: fundamentos teóricos e clínicos. 2. ed. Porto Alegre: Artmed, 2005.

ETCHEGOYEN, R. H. Fundamentos da técnica psicanalítica. 2. ed. Porto Alegre: Artmed, 2004.

FREUD, S. As perspectivas futuras da terapêutica psicanalítica. In: FREUD, S. Edição standard brasileira das obras psicológicas completas de Sigmund Freud. Rio de Janeiro: Imago, 2006 a. v. XI. (Original de 1910).

. A dinâmica da transferência. In: FREUD, S. Edição standard brasileira das obras psicológicas completas de Sigmund Freud. Rio de Janeiro: Imago, 2006b. v. XII. (Original de 1912).

. Sobre o início do tratamento: novas recomendações a técnica da psicanálise. In:

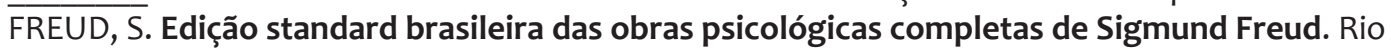
de Janeiro: Imago, 2006c. v. XII. (Original de 1913).

GROTSTEIN, J. S. Um facho de intensa escuridão: o legado de Wilfred Bion à psicanálise. Porto Alegre: Artes Médicas, 2010.

JANUARIO, L. M.;TAFURI, M.I.Arelaçãotransferencial para além da interpretação: reflexõesa partir da teoria de Winnicott. Ágora, Rio de Janeiro, v. 14, n. 2, dez. 2011. Disponível em: <http://www. scielo.br/scielo.php?pid=S1516-14982011000200007\&script=sci_arttext $>$.Acessoem:13ago.2012. KLEIN, M. As origens da transferência. In: KLEIN, M. Inveja e gratidão e outros trabalhos (19461963). Rio de Janeiro: Imago Editora, 1991, p. 70-80. (Originalmente publicado em 1952)

KLAUTAU, P.; SALEM, P. Dependência e construção da confiança: a clínica psicanalítica nos limites da interpretação. Natureza Humana, São Paulo, v. 11, n. 2, fev. 2009. Disponível em: <http:// pepsic.bvsalud.org/scielo.php?.pid=S1517-24302009000200002\&script=sci_arttext $>$. Acesso em: 6 ago. 2012.

KHAN, M. Introdução de M. Masud Khan. In: WINNICOTT, D. Da pediatria à psicanálise: obras escolhidas. Rio de Janeiro: Imago, 2000. 
MELEGA, M. P. Origens literárias do modelo psicanalítico da mente. Jornal de Psicanálise, São Paulo, v. 44, n. 80, jun. 2011. Disponível em: <http://pepsic.bvsalud.org/scielo.php?script=sci_art text\&pid=S0103-58352011000100020>. Acesso em: 13 ago. 2012.

OGDEN, T. H. Os sujeitos da psicanálise. São Paulo: Casa do Psicólogo, 1996.

SAFRA, G. Momentos mutativos em psicanálise: uma visão winnicottiana. São Paulo: Casa do Psicólogo, 1995.

SALVITTI, A. Psicose e ética do pensador na clínica de Bion: panorama dos artigos dos anos 50. Impulso, Piracicaba, v. 21, n. 52, p. 57-64, 2011. Disponível em: <https://www.metodista.br/revistas/revistas-unimep/index.php/impulso/article/view/363/583>. Acesso em: 12 ago. 2012.

WINNICOTT, D. W. O ambiente e os processos de maturação: estudos sobre a teoria do desenvolvimento emocional. 3. ed. Porto Alegre: Artes Médicas, 1990. (Original de 1979).

. O ódio na contratransferência. In: WINNICOTT D. W. Da pediatria à psicanálise. Rio de Janeiro: Imago, 2000. (Original de 1949).

. A comunicação entre o bebê e a mãe e entre a mãe e o bebê: convergências e divergências. In: WINNICOTT D. W. O bebê e suas mães. São Paulo: Martins Fontes, 2002. p. 79-92. (Original de 1967).

. Conseqüências da psicose parental para o desenvolvimento emocional da criança. In: WINNICOTT D. W. A família e o desenvolvimento individual. 3. ed. São Paulo: Martins Fontes, 2005. (Original de 1961).

ZIMERMAN, D. E. Fundamentos psicanalíticos: teoria, técnica e clínica. Uma abordagem didática. Porto Alegre: Artmed, 1999.

- Uma ampliação da aplicação, na prática psicanalítica, da noção de continente em Bion. Interações, Coimbra, n. 1, Nov. 2011. Disponível em: <http://interações-ismt.com/index. php/revista/article/view/239/246>. Acesso em: 10 ago. 2012.

\section{DADOS DOS AUTORES}

JuLIA GiRnos Elias DE SOUZA

Universidade Federal de São Carlos (UFSCAR). Graduada em Psicologia pela Universidade Estadual de Maringá (2007), Especialista em Psicoterapias de Orientação Psicanalítica pelo Departamento de Medicina da Universidade Federal de São Carlos (2012).

Érico Bruno Viana Campos

Universidade Estadual Paulista Júlio de Mesquita (UNESP). Graduado em Psicologia pela Universidade de São Paulo (2002), mestrado (2004) e doutorado (2009) em Psicologia pela Universidade de São Paulo. É professor assistente doutor do Departamento de Psicologia da

Faculdade de Ciências da Universidade Estadual Paulista Júlio de Mesquita em Bauru.

Recebido: 25/02/2013

Aprovado: 06/05/2014 